\title{
AFECTACIONES A LA LIBERTAD DE CIRCULACIÓN DERIVADAS DEL ESTADO DE ALARMA DECLARADO A CAUSA DE LA CRISIS «COVID-19»"
}

\author{
Juan Fernando Durán Alba \\ Profesor Titular de Derecho Constitucional \\ Universidad de Valladolid
}

Cómo citar este artículo / Citation: Durán Alba, J.F. (2020). Afectaciones a la libertad de circulación derivadas del estado de alarma. Biglino Campos, P.; Durán Alba, F. Los efectos horizontales de la covid-19 sobre el ordenamiento constitucional: estudios sobre la primera oleada, Colección Obras Colectivas, Fundación Manuel Giménez Abad, Zaragoza. DOI: https://doi.org/10.47919/FMGA.OC20.0010

SUMARIO: I. INTRODUCCIÓN. II. LA LIBERTAD DE CIRCULACIÓN EN LA CONSTITUCIÓN ESPAÑOLA: 1. Conformación de la libertad de circulación como contenido del artículo 19 CE. 2. La libertad de circulación en la jurisprudencia del Tribunal Constitucional. III. LA LIBERTAD DE CIRCULACIÓN EN EL RD 463/2020, DE 14 DE MARZO, Y SUS SUCESIVAS PRÓRROGAS: 1. Una cuestión previa: ¿libertad personal o libertad de circulación? 2. La secuencia normativa de las restricciones. 3. La regresión: apuntes sobre la vuelta al estado de alarma y su incidencia sobre la libertad de circulación. 4. Reflexiones sobre las restricciones a la libertad de circulación. IV. BIBLIOGRAFÍA.

\footnotetext{
${ }^{1}$ He tenido la oportunidad de discutir algunas de las ideas que se contienen en el presente texto en el marco de la I Jornada del Observatorio Internacional de Derechos Humanos 2020 que, bajo el título: Problemas constitucionales de la restricción de la libertad de circulación en los tiempos del Covid-19, fue auspiciada por la Academia Interamericana de Derechos Humanos, que amablemente me invitó a participar como ponente, y que tuvo lugar durante los días 2-4 de septiembre de 2020 en formato vía Zoom.
} 


\section{INTRODUCCIÓN}

Parece entrañar una cierta paradoja el carácter dinámico que tiene el contenido y alcance de la libertad de circulación, concretado en la libertad deambulatoria, con una cierta complacencia, si no indolencia, respecto a la conflictividad que ha generado ante los tribunales, más allá de su invocación recurrente en materia de extranjería. Sin embargo la situación de crisis sanitaria que padecemos ha revivido a este derecho, confiriéndole un papel de protagonista indiscutible entre los derechos susceptibles de afrontar restricciones para hacer frente a la presente pandemia.

Las perplejidades que para el jurista presentaba la declaración de lo que llamaré el "primer estado de alarma pandémico" y su estela de prórrogas, se encontraban, por lo menos, bien perimetradas espaciotemporalmente. Posiblemente, para lo que no estábamos preparados es para la cogobernanza, entiéndaseme bien, estrictamente desde la perspectiva que aquí nos ocupa, que es la de las limitaciones a los derechos fundamentales que consiente una situación de emergencia sanitaria como la presente.

Por razones de espacio, las siguientes consideraciones están referidas a ese "primer estado de alarma pandémico", aunque, por razones comprensibles, no he podido dejar de avanzar algunas consideraciones con los dos estados de alarma que lo han sucedido recientemente puesto que, en estos, la libertad de circulación no ha abandonado su posición preponderante... ¿de víctima?

Apenas unas indicaciones preliminares sobre el significado de la libertad de circulación en nuestro ordenamiento constitucional, pues no es el objeto de este trabajo construir dogmáticamente este derecho, servirán para introducirnos en el examen de las afectaciones que ha sufrido a lo largo de estos meses y tratar de evaluar su "calidad constitucional". Sí, es este un aspecto especialmente controvertido, pues a lo largo de estos meses se ha ido abriendo paso la idea de que el aparato normativo con el que está pertrechado nuestro ordenamiento jurídico no es el idóneo -o no lo suficiente- para intervenir en una libertad que se integra dentro de las que alguna literatura norteamericana califica como derechos frente a la cólera del Estado. Más que resolver esta cuestión compleja creo estar en condiciones, por lo menos, de aportar, siquiera esbozar seguramente, otra perspectiva distinta a la esgrimida habitualmente para considerar la resbaladiza dicotomía de la restricción frente a suspensión de los derechos fundamentales. 


\section{LA LIBERTAD DE CIRCULACIÓN EN LA CONSTITUCIÓN ESPAÑOLA}

1. Conformación de la libertad de circulación como contenido del artículo 19 CE

Sin pretender extenderme en lo que podría parecer una discusión un tanto bizantina, sí quiero apuntar que existe un cierto contraste de pareceres acerca de la conformación del contenido artículo $19 \mathrm{CE}^{2}$ entre el Tribunal Constitucional y algunos autores; mientras para el primero, el precepto integra cuatro derechos 0 libertades distintas ${ }^{3}$, los segundos refieren la existencia de un único derecho o libertad con cuatro facetas o vertientes distintas ${ }^{4}$. Lo cierto es que tan rotunda afirmación del tribunal parece compadecerse mal con el propio tenor literal del precepto y, sobre todo, de su inciso final, que contiene una de esas apelaciones sectoriales a la igualdad que menudean por el texto constitucional, más allá del enunciado del art. $14 \mathrm{CE}$, cuando se alude expresamente a que: "Este derecho no podrá ser limitado por motivos políticos o ideológicos", o lo que es lo mismo, no caben tratamientos discriminatorios en la materia por estas razones.

Las consideraciones del tribunal sugieren algún interrogante: ¿únicamente se refiere esta prohibición al derecho de entrada o al de salida al territorio nacional (la Constitución emplea el término derecho en singular, el tribunal habla de cuatro distintos)? Llevar la afirmación a su extremo conduciría a un resultado absurdo, pues el inciso final del art. 19 CE casa bien con la tormentosa tradición de la libertad de circulación y residencia, en la base de cuyas restricciones se encuentran motivos de esa índole (discriminatorios) y que afectaron tanto a la libertad deambulatoria como a la libertad de fijar residencia, con la existencia de un "Derecho ambulatorio punitivo", que contenía sanciones de extrañamiento (ubicadas ya, a modo de precedente, en el mismo ostracismo heleno) o la obligación de que determinadas comunidades residieran en lugares

\footnotetext{
2 "Los españoles tienen derecho a elegir libremente su residencia y a circular por el territorio nacional.

Asimismo, tienen derecho a entrar y salir libremente de España en los términos que la ley establezca. Este derecho no podrá ser limitado por motivos políticos o ideológicos".

3 'El art. 19 CE reconoce a 'los españoles' cuatro derechos fundamentales distintos: el derecho a elegir libremente su residencia, el derecho a circular por el territorio nacional, el derecho a entrar en España y el derecho a salir libremente del territorio nacional" (STC 72/2005, de 4 de abril, FJ 5); entre los autores la posición del tribunal es recogida directamente sin matización alguna por Losada González, H., 2018: 568. También Delgado Ramos, D., 2018: 481.

${ }^{4}$ Vid. Goizueta Vértiz, J., 2018: 457.
} 
determinados. No deja de ser cierto que los pronunciamientos del tribunal en esta materia no son especialmente escrupulosos, no existe una gran construcción del contenido del artículo $19 \mathrm{CE}$, como sí la hay con otros derechos, y tienen más bien un marcado carácter instrumental e introductorio para abordar las cuestiones que, de forma más recurrente, se han llevado a la justicia constitucional en relación con estos derechos: las cuestiones de extranjería (singularmente entrada y salida de extranjeros en las que ahora no cumple detenerse).

Acaso, la disección del precepto en distintos derechos permite al tribunal distinguir qué derechos de los que integra el artículo 19 están más estrechamente vinculados a la dignidad de la persona. Como resulta sobradamente conocido, la gradación de la proximidad de un derecho a la dignidad de la persona -por lo demás, no bien acogida por la doctrina- se erige como uno de los criterios que ha venido usándose para construir jurisprudencialmente un eventual régimen distinto en los que respecta a los derechos fundamentales entre nacionales y extranjeros. Es decir, aunque la conclusión haya que deducirla del pronunciamiento, mientras la libertad de circulación dentro de las fronteras del Estado sí está más estrechamente vinculada con la dignidad, "la circulación a través de las fronteras del Estado" (la entrada y salida) y la libertad de residencia no, derivándose, en consecuencia, un régimen distinto para ciudadanos y extranjeros ${ }^{5}$.

De no ser así y, por lo tanto, aplicarse las aseveraciones del tribunal a todos los derechos del artículo $19 \mathrm{CE}$, la libertad personal de circulación quedaría profundamente devaluada, siendo como es emanación de la libertad personal. Una cosa es que ambas libertades tengan contenidos precisos y que, por ello respecto de la libertad deambulatoria, al ser un derecho autónomo a la libertad personal recogida en el artículo $17 \mathrm{CE}$, se admita un canon distinto entre ambos derechos para evaluar la proporcionalidad de las eventuales restricciones ${ }^{6}$, y otra bien distinta sostener de forma tan rotunda tal desconexión, que nos llevaría a

\footnotetext{
5 "La libertad de circulación a través de las fronteras del Estado, y el concomitante derecho a residir dentro de ellas, no son derechos imprescindibles para la garantía de la dignidad humana (art. 10.1 C.E., y STC 107/1984, fundamento jurídico $3^{\circ}$ ), ni por consiguiente pertenecen a todas las personas en cuanto tales al margen de su condición de ciudadano. De acuerdo con la doctrina sentada por la citada Sentencia, es pues lícito que las leyes y los tratados modulen el ejercicio de esos derechos en función de la nacionalidad de las personas, introduciendo tratamientos desiguales entre españoles y extranjeros en lo que atañe a entrar y salir de España, y a residir en ella" (STC 94/1993, de 22 de marzo, FJ 3)".

6 "Si se llegara a la conclusión de que la medida impuesta afecta a la libre circulación de las personas, las exigencias de previsión legal y proporcionalidad debieran ser analizadas desde la perspectiva de un canon diferente al requerido por el derecho a la libertad personal" [STC 169/2001, de 16 de julio, FJ 4,a)].
} 
escenarios un tanto absurdos allí donde la libertad de circulación haya que reconocerla por derivación de la libertad personal. Porque, sin ella, esa libertad personal queda en parte vacía de contenido. Mutatis mutandis, algo parecido a lo que ha hecho el tribunal con el art. 23.2 CE, que únicamente recoge de forma expresa el acceso a los cargos públicos, pero que la jurisprudencia del tribunal se ha encargado de declarar que integra el derecho a conservar el cargo (no ser removido contra legem) y al ius in officium, pues si no el derecho quedaría vacío de contenido. En fin, mi opinión personal, desde el máximo respeto al Tribunal Constitucional, es que el artículo 19 CE reconoce una única libertad, genéricamente denominada derecho a la libertad de circulación y residencia, con el contenido allí detallado.

\section{La libertad de circulación en la jurisprudencia del Tribunal Constitucional}

Si dejamos de un lado los problemas de extranjería, que por sí mismos darían para unas jornadas temáticas, la intensidad contenciosa del derecho parece escasa. Las apelaciones a la libertad de circulación en relación con las privaciones de libertad se han vehiculado más habitualmente a través del derecho a la libertad personal recogido en el art. $17 \mathrm{CE}$. Por cierto, que estamos ante un derecho tradicionalmente conformado como de libertad personal, por lo que los conflictos derivados de la circulación de bienes, servicios económicos se entienden que son emanación, en su caso, de otro derecho, la libertad de empresa (art. $38 \mathrm{CE})$ :

“También hay que poner aquel precepto en conexión con el 139.2 CE, pues toda medida que impida o fomente el traslado de empresas, incidirá lógicamente en la libertad de circulación y, por tanto, en la libertad de empresas. Efectivamente, 'el traslado de industrias guarda estrecha relación con los principios de la Constitución económica a los que acaba de hacerse referencia, no sólo en la medida en que la actividad de traslado industrial de un lugar a otro dentro del Estado implica desplazamiento espacial de medios productivos y circulación, en consecuencia, de bienes y personas por el territorio nacional, sino también por cuanto constituye una relevante manifestación de la libertad de empresa que el art. 38 de la Constitución reconoce (...), entendida aquí como libertad de actuación, de elección por la empresa de su propio mercado, cuyo ejercicio en condiciones básicas de igualdad queda constitucionalmente garantizado, y cuyo respeto marca los 
límites dentro de los que necesariamente han de moverse los poderes constituidos al adoptar medidas que incidan sobre el sistema económico de nuestra sociedad' (SSTC 37/1981, de 16 de noviembre, FJ 2; 4/1990, de 5 de abril, FJ 4; y 96/2002, de 25 de abril, FJ 11)"7.

Desde el punto de vista del conflicto entre derechos, las controversias más recurrentes han tenido que ver con el derecho de reunión y manifestación (artículo $21 \mathrm{CE}$ ), por razones fácilmente comprensibles que todos hemos padecido en alguna ocasión. En este punto, el Tribunal Constitucional, partiendo de la inexistencia de un ordo prelationis de los derechos fundamentales reconocidos en nuestra Constitución, sí ha venido otorgando una prevalencia al derecho de reunión y manifestación sobre la libertad de circulación, lo que claro está no excluye pronunciamientos en sentido contrario llegado el caso:

"El único bien constitucional protegible, que podrían haber infringido los manifestantes es el derecho a la libre circulación por el territorio nacional de los conductores que hubieron de soportar el transcurso de la manifestación. Este derecho subjetivo tiene también una dimensión constitucional al estar proclamado como derecho fundamental por el art. 19 y podría, por tanto, erigirse en un límite al derecho de manifestación, pues, de conformidad con lo dispuesto en el art. 11.2 del Convenio Europeo de Derechos Humanos, el ejercicio del derecho de reunión pacifica puede ser objeto de medidas restrictivas siempre que sean «necesarias, en una sociedad democrática, para la protección de los derechos y libertades ajenos», de entre los que hay que estimar incluido el derecho «a la libre circulación de los ciudadanos por el territorio nacional» (art. 19 C.E.). Pero lo que también resulta obligado dilucidar es si la exclusiva protección de dicho derecho es un límite suficiente para negar el libre ejercicio del derecho de reunión pacífica y, si aquella restricción alcanzó en la práctica el grado de intensidad suficiente para permitir el sacrificio del derecho contemplado en el art. 21 de la Constitución"8.

\footnotetext{
${ }^{7}$ Las cursivas son mías (véase el ATC 207/2005, de 10 de mayo, FJ 7).

${ }^{8}$ STC 59/1990, de 29 de marzo, FJ 7. Así pues, la ponderación entre ambos derechos puede llevar a que la protección de la libertad de circulación consienta restricciones a los derechos de reunión y manifestación: "los hechos relacionados en la resolución gubernativa en conjunción con la habitualidad o reiteración del ejercicio del derecho por parte de los manifestantes, suponen una razón fundada, una motivación suficiente y concreta de las modulaciones del derecho de reunión y manifestación tendentes a evitar o intentar reparar el sacrificio desproporcionado de otros bienes constitucionales, en concreto, de la libertad de circulación del resto de ciudadanos no
} 
Por último, en el marco de la permanente disputa competencial entre el Estado y las Comunidades Autónomas, el Tribunal Constitucional ha avalado el recurso por parte del Estado a la libertad de circulación como argumento para justificar la competencia estatal para el establecimiento de condiciones básicas de ejercicio de derechos y deberes constitucionales, regulando el supuesto objeto de controversia las tarjetas de estacionamiento para personas con discapacidad con la finalidad de que existiera un régimen uniforme en el todo el territorio nacional, esto es, poniendo en conexión la libertad de circulación y el artículo 149.1.1 CE:

"Pues bien, para la cobertura de la posible intervención normativa estatal en relación con las tarjetas de estacionamiento de personas discapacitadas cabe la puesta en juego de un título competencial que está recogido en el Real Decreto cuestionado y que ha sido esgrimido en sus alegaciones por parte de la Abogacía del Estado en este conflicto: la competencia estatal para el establecimiento de condiciones básicas de ejercicio de derechos y deberes constitucionales (art. 149.1.1 CE), que presta sustento a la introducción de algunos requisitos y condiciones de acceso al derecho de uso de estas tarjetas, los cuales se introducen como garantía de la igualdad básica de los beneficiarios de estas autorizaciones en todo el territorio del Estado. Concretamente, el derecho fundamental en cuyo ejercicio interviene la normativa estatal con el propósito de asegurar esa homogeneidad regulatoria básica es la libertad de circulación (art. 19 CE). [...] La Constitución garantiza a todos los españoles el derecho a circular con libertad por todo el territorio del Estado, y es evidente que una buena parte de esa circulación se realiza mediante vehículos a motor y a través de las vías públicas. En ese entorno, las personas con discapacidad encuentran especiales dificultades para ejercer ese derecho por sus limitaciones físicas de movilidad por lo que, como ya hemos destacado, los poderes públicos -cada uno en el ámbito de sus competencias- deben promover las condiciones para que la libertad e igualdad de los miembros de ese colectivo sean reales y efectivas, y para que se remuevan los obstáculos que impidan o dificulten su plenitud (art. 9.2 CE). En el mismo sentido, y de manera más

manifestantes. Sin olvidar que el sindicato demandante ha podido llevar a cabo su campaña de manifestaciones, entendemos que en este caso la Delegación del Gobierno ha realizado la ponderación casuística que le es exigible constitucionalmente, motivando suficientemente la adopción de la medida en cuestión por razón del sacrifico desproporcionado de la libertad de circulación que han venido asumiendo los vecinos de esa zona de Ceuta de forma prolongada e intensiva" (STC 193/2011, de 12 de diciembre, FJ 5). 
específica para los disminuidos físicos, sensoriales y psíquicos, el art. $49 \mathrm{CE}$ exige también a los poderes públicos que les ampare "especialmente para el disfrute de los derechos que este Título otorga a todos los ciudadanos". En cumplimiento de ese doble mandato constitucional, tanto general como específico (arts. 9.2 y $49 \mathrm{CE}$ ), es indudable que el Estado cuenta con cobertura para establecer una serie de condiciones ex art. 149.1.1 CE, que aseguren la libre circulación por todo nuestro territorio de personas que padecen algún tipo de discapacidad (art. $19 \mathrm{CE}$ ), en términos de igualdad sustancial. Esa circulación se realizará por medio de vehículos especiales, manejados por la propia persona discapacitada o por terceros, y comprende sin duda su estacionamiento en la vía pública, que es una actividad complementaria esencial de la circulación"?.

\section{LA LIBERTAD DE CIRCULACIÓN EN EL RD 463/2020, DE 14 DE MARZO, Y SUS SUCESIVAS PRÓRROGAS}

1. Una cuestión previa: ¿libertad personal o libertad de circulación?

Aunque no han faltado autores que han vinculado la libertad personal con la libertad deambulatoria ${ }^{10}$, lo cierto es que las libertades reconocidas en los artículos 17 y 19 CE tienen un carácter manifiestamente autónomo, esto es, aunque la libertad de circulación pueda entenderse como concreción de la libertad personal ${ }^{11}$, "las exigencias de previsión legal y proporcionalidad debieran ser analizadas desde la perspectiva de un canon diferente al requerido por el derecho a la libertad personal" [STC 169/2001, de 16 de julio, FJ 4.a)]. Sin perjuicio de lo expuesto y, a pesar de las expresas y privilegiadas menciones que se realizan en las normas objeto del presente estudio a la libertad de circulación, lo cierto es que no han faltado supuestos que parecen encajar más bien en una restricción de la libertad personal amparada en el art. $17 \mathrm{CE}$, como es el confinamiento domiciliario o en otro establecimiento (sanitario o de otra índole, habilitado al efecto), con limitación absoluta de la libertad deambulatoria más allá del recinto.

\footnotetext{
${ }^{9}$ Las cursivas son mías (véase STC 18/2017, de 2 de febrero, FJ 3).

${ }^{10}$ Díez-Picazo, L. M. ${ }^{\text {a }}$, 2005: 280; si bien el autor, reconociendo la estrecha relación entre ambas libertades, "el derecho a la libertad hace referencia a la libertad deambulatoria en cuanto tal, la libertad de residencia y circulación hace referencia a los lugares donde uno puede estar o por donde puede moverse" (ídem).

${ }^{11}$ Bastida Freijedo, F., 2001: 153.
} 
Así ha sucedido con el confinamiento de los turistas extranjeros que se alojaban en el hotel de la localidad tinerfeña de Adeje. Por parte de la Consejería de Sanidad del Gobierno de Canarias se dictó Orden, de 24 de febrero de 2020 (modificada ulteriormente, el 27 de febrero de 2020, en función de las distintas circunstancias personales del personal alojado en el establecimiento hotelero), por la que se dispuso la permanencia obligatoria de todos los huéspedes alojados en hotel, hasta su valoración por parte del correspondiente personal sanitario; la medida vino motivada al detectarse el positivo en covid-19 de un ciudadano italiano, huésped del hotel. Los accesos del recinto fueron vigilados por miembros de las fuerzas y cuerpos de seguridad. Las medidas fueron ratificadas en vía judicial, primero, por Auto del Juzgado de Instrucción número 1 de Arona (de guardia, dado el carácter festivo de la fecha de autos) y, posteriormente, por Auto del Juzgado de lo Contencioso-Administrativo número 1 de Santa Cruz de Tenerife, de 2 de marzo de 2020.

Resulta sumamente curioso como esta última resolución, tras examinar la habilitación normativa para adoptar las medidas ${ }^{12}$, valorar las diferentes circunstancias a las que se veían sometidos los individuos aislados en el establecimiento hotelero, así como los distintos informes sanitarios, en ningún momento se identifica el derecho o derechos que pueden quedar afectados por las medidas restrictivas, más allá de unas genéricas apelaciones a la libertad $u$ otros derechos fundamentales en los términos del artículo 8.5 de la Ley reguladora de la Jurisdicción Contencioso-Administrativa.

Bien distinto es el supuesto del Auto del Juzgado de Primera Instancia e Instrucción de Palencia, en funciones de guardia ${ }^{13}$. La resolución judicial se dicta a instancias de la autoridad sanitaria, ante un diagnóstico positivo en covid-19, tras una prueba realizada en el Hospital Río Carrión de Palencia, solicitando el paciente inmediatamente el alta voluntaria. En este caso la resolución judicial sí identifica el derecho fundamental directamente concernido por la medida sanitaria de aislamiento, citando expresamente el artículo 17.1 CE (además de los artículos

\footnotetext{
${ }^{12}$ En concreto, los artículos: 2 de la Ley Orgánica 3/1986, de 14 de abril, de medidas especiales en materia de salud pública, 26 de la Ley Orgánica 14/1986, de 25 de abril, General de Sanidad, y 25.2 de la Ley del Parlamento de Canarias 11/1994, de 26 de julio, de Ordenación Sanitaria de Canarias.

${ }^{13}$ La versión de la resolución judicial consultada carece de fecha, la referencia, tomada del portal Poder Judicial, es de 14 de abril de 2020 <http://www.poderjudicial.es/cgpj/es/Poder-Judicial/Salade-Prensa/Notas-de-prensa/Un-juzgado-de-Palencia-ordena-volver-a-internar-a-un-paciente-concoronavirus-que-solicito-el-alta-voluntario>
} 
15, derecho a la vida e integridad física, y 43, derecho a la protección de la salud, que han de entenderse en contraste con el anterior) ${ }^{14}$.

Los aislamientos o confinamientos como los descritos, en los que los individuos afectados tengan absolutamente privada la libertad deambulatoria más allá del lugar de confinamiento, no son supuestos en los que directamente se produzca una afectación de la libertad de circulación (que claramente también queda limitada, como sin duda otros derechos por conexión) sino de restricción de la libertad personal. Este tipo de restricciones a la libertad, de acuerdo con nuestro Tribunal Constitucional, han de interpretarse de acuerdo con lo dispuesto en los tratados válidamente suscritos por nuestro país (por todas, SSTC 112/1988, de 12 de junio, FJ 3, y 24/1993, de 21 de enero, FJ 5) sin que quepa omitir en este particular las indicaciones a la prevención sanitaria que se contienen en el Convenio de Roma en relación, precisamente, con el derecho de libertad, cuando en el artículo 5.1, letra e), se dispone que: "Toda persona tiene derecho a la libertad y a la seguridad. Nadie puede ser privado de su libertad, salvo en los casos siguientes y con arreglo al procedimiento establecido por la ley:

\section{$[\ldots]$}

»e) Si se trata del internamiento, conforme a derecho, de una persona susceptible de propagar una enfermedad contagiosa, de un enajenado, de un alcohólico, de un toxicómano o de un vagabundo" (las cursivas son del autor del presente texto).

No obstante los supuestos referidos, emanación de actuaciones concretas amparadas en la legislación sanitaria, lo cierto es que las disposiciones dictadas con ocasión del estado de alarma se refieren expresamente a la libertad de circulación. Habrá de examinarse a continuación si dicha asimilación entre la medida y el derecho afectado resulta correcta ${ }^{15}$.

\footnotetext{
${ }^{14}$ Por cierto, aunque no parezca que en este caso se alegue de contrario, la resistencia a permanecer en el establecimiento hospitalario, habida cuenta de que el paciente debía recibir tratamiento médico, no podría ampararse en el propio artículo $17 \mathrm{CE}$, como emanación de la libertad personal, en tanto que el Tribunal Constitucional tiene declarado que "la libertad de rechazar tratamientos terapéuticos, como manifestación de la libre autodeterminación de la persona no puede entenderse incluida en la esfera del art. 17.1 de la Constitución Española" (STC 120/1990, de 27 de junio, FJ 11).

${ }^{15}$ Llama la atención que mediante una orden ministerial se suspende expresamente el régimen salidas de permiso y otras salidas programadas de los internos en establecimiento penitenciario "salvo por causas de fuerza mayor o situación de necesidad para evitar los desplazamientos que están prohibidos por el artículo 7 del Real Decreto 463/2020, de 14 de marzo" [véase el artículo 1 , letra b), de la Orden INT/227/2020, de 15 de marzo, en relación con las medidas que se adoptan en el ámbito de Instituciones Penitenciarias al amparo del Real Decreto 463/2020, de 14 de marzo,
} 


\section{La secuencia normativa de las restricciones ${ }^{16}$.}

La declaración del estado de alarma. La disposición de "entrada" es el RD 463/2020, de 14 de marzo, por el que se declara el estado de alarma para la gestión de la situación de crisis sanitaria ocasionada por el COVID-19. El decreto no se acompaña de un lúcido esfuerzo justificativo, haciendo hincapié, en lo que aquí interesa, en que las medidas "son las imprescindibles para hacer frente a la situación, resultan proporcionadas a la extrema gravedad de la misma y no suponen la suspensión de ningún derecho fundamental". La norma incorpora un artículo 7 específicamente consagrado a la "limitación de la libertad de circulación de las personas". El precepto parte de la interdicción de la circulación con la indicación de una serie de salvedades derivadas de la realización de actividades que expresamente se excepcionan, que son:

a) Adquisición de alimentos, productos farmacéuticos y de primera necesidad.

b) Asistencia a centros, servicios y establecimientos sanitarios.

c) Desplazamiento al lugar de trabajo para efectuar su prestación laboral, profesional o empresarial.

d) Retorno al lugar de residencia habitual.

e) Asistencia y cuidado a mayores, menores, dependientes, personas con discapacidad o personas especialmente vulnerables ${ }^{17}$.

f) Desplazamiento a entidades financieras y de seguros.

g) Por causa de fuerza mayor o situación de necesidad.

por el que se declara el estado de alarma para la gestión de la situación de crisis sanitaria ocasionada por el COVID-19, BOE de 15 de marzo de 2020]. Las restricciones no se flexibilizaron (entre ellas los permisos de salida) hasta la adopción de la Orden INT/407/2020, de 12 de mayo, por la que se adoptan medidas para flexibilizar las restricciones establecidas en el ámbito de Instituciones Penitenciarias al amparo del Real Decreto 463/2020, de 14 de marzo, por el que se declara el estado de alarma para la gestión de la situación de crisis sanitaria ocasionada por el COVID-19. (BOE de 13 de mayo).

${ }^{16}$ Puede encontrarse un exhaustivo análisis de cada una de las disposiciones relativas al estado de alarma y sus sucesivas prórrogas, con un alcance mayor que el del presente estudio limitado a la libertad de circulación, en Álvarez García, V.; Arias Aparicio, F. y Hernández Díez, E. (2020): 112-127.

17 Véase un planteamiento preciso sobre la incidencia de las restricciones a la libertad de circulación en los colectivos más vulnerables en Presno, M., 2020: 52-63. 
h) Cualquier otra actividad de análoga naturaleza que habrá de hacerse individualmente, salvo que se acompañe a personas con discapacidad o por otra causa justificada ${ }^{18}$.

El resto de disposiciones del precepto se refiere a concreciones que podrían calificarse de "técnicas", pues se dirigen al modo en el que han de hacerse los desplazamientos (pueden realizarse en vehículo para las actividades expresamente excepcionadas) o a las autoridades encargadas de aplicar la norma $^{19}$. Más adelante, la disposición adicional primera del real decreto añade una excepción en favor del personal extranjero acreditado como miembros de las misiones diplomáticas, cuando establece que: "Queda exceptuado de las limitaciones a la libertad de circulación el personal extranjero acreditado como miembro de las misiones diplomáticas, oficinas consulares y organismos internacionales sitos en España, tanto para desplazamientos dentro del territorio nacional, como a su país de origen o a terceros Estados, en los que se encuentre igualmente acreditado, siempre que se trate de desplazamientos vinculados al desempeño de funciones oficiales" 20 .

La primera modificación del precepto se produjo mediante el Real Decreto 465/2020, de 17 de marzo, por el que se modifica el Real Decreto 463/2020, de 14 de marzo, por el que se declara el estado de alarma para la gestión de la situación de crisis sanitaria ocasionada por el COVID-19; la norma simplifica la

${ }^{18}$ En aplicación de este supuesto, en relación con el contenido en la letra a), el Juzgado de lo Contencioso-Administrativo núm. 2 de Vigo anuló la sanción de 601 euros impuesta por la Subdelegación del Gobierno de Pontevedra, el 12 de mayo de 2020, a una mujer que había ido a comprar alimentos acompañada de su hijo, recién operado de la rodilla e imposibilitado para la conducción <http://www.poderjudicial.es/cgpj/es/Poder-Judicial/Noticias-Judiciales/El-Juzgadoanula-una-multa-impuesta-a-una-mujer-en-Vigo-por-ir-a-la-compra-con-su-hijo-durante-el-estadode-alarmas

${ }^{19}$ En relación con este particular, resulta relevante la Orden INT/226/2020, de 15 de marzo, por la que se establecen criterios de actuación para las Fuerzas y Cuerpos de Seguridad en relación con el Real Decreto 463/2020, de 14 de marzo, por el que se declara el estado de alarma para la gestión de la situación de crisis sanitaria ocasionada por el COVID-19 (BOE, de 16 de marzo de 2020), por cuanto algunos de estos criterios están directamente referidos a las actuaciones en relación con las medidas restrictivas de la libertad de circulación, regulando, por ejemplo, el establecimiento de controles y dispositivos de seguridad en vías y espacios públicos (artículo 4).

${ }^{20} \mathrm{~V}$. Álvarez ha considerado que el artículo 7 del real decreto se sustenta en el artículo 11, letra a), LO 4/1981, de 1 de junio de los estados de alarma, excepción y sitio. y parece ser una concreción del artículo 3 LO 3/1986, de 14 de abril, de Medidas Especiales en materia de Salud Pública ("Con el fin de controlar las enfermedades transmisibles, la autoridad sanitaria, además de realizar las acciones preventivas generales, podrá adoptar las medidas oportunas para el control de los enfermos, de las personas que estén o hayan estado en contacto con los mismos y del medio ambiente inmediato, así como las que se consideren necesarias en caso de riesgo de carácter transmisible"), lo que le confiere "relevancia simbólica" (2020: 13). 
última de las excepciones, contenida en la letra h) del artículo 7 y que pasa a quedar sencillamente redactada como "Cualquier otra actividad de análoga naturaleza", mientras que la alusión a las personas discapacitadas u otras circunstancias se llevan al enunciado del precepto ${ }^{21}$.

Estrictamente, las restricciones a las libertades contenidas en el artículo 19 CE no se extraen exclusivamente del real decreto. Así, algo más que un carácter técnico tiene la subsiguiente Orden INT/239/2020, de 16 de marzo, por la que se restablecen los controles en las fronteras interiores terrestres con motivo de la situación de crisis sanitaria ocasionada por la COVID-1922, cuando establece un régimen específico de prohibición de entrada en el territorio nacional, salvo para:

21 "Durante la vigencia del estado de alarma las personas únicamente podrán circular por las vías o espacios de uso público para la realización de las siguientes actividades, que deberán realizarse individualmente, salvo que se acompañe a personas con discapacidad, menores, mayores, o por otra causa justificada".

${ }^{22}$. (BOE de 16 de marzo de 2020), la disposición se complementó posteriormente con una Orden INT/248/2020, de 16 de marzo, por la que se establecen criterios de actuación para las Fuerzas y Cuerpos de Seguridad ante el restablecimiento temporal de controles fronterizos (BOE, de 18 de marzo). La medida se prorrogó mediante: Orden INT/335/2020, de 10 de abril, por la que se prorrogan los controles en las fronteras interiores terrestres restablecidos con motivo de la situación de crisis sanitaria ocasionada por el COVID-19 (BOE de 11 de abril de 2020); Orden INT/356/2020, de 20 de abril, por la que se prorrogan los criterios para la aplicación de una restricción temporal de viajes no imprescindibles desde terceros países a la Unión Europea y países asociados Schengen por razones de orden público y salud pública con motivo de la crisis sanitaria ocasionada por el COVID-19 (BOE de 21 de abril de 2020); más adelante por Orden INT/368/2020, de 24 de abril, por la que se prorrogan los controles en las fronteras interiores terrestres restablecidos con motivo de la situación de crisis sanitaria ocasionada por el COVID-19; por Orden INT/396/2020, de 8 de mayo, por la que se prorrogan los controles en las fronteras interiores terrestres con motivo de la situación de crisis sanitaria ocasionada por el COVID-19; Orden INT/401/2020, de 11 de mayo, por la que se restablecen temporalmente los controles en las fronteras interiores aéreas y marítimas, con motivo de la situación de crisis sanitaria ocasionada por el COVID-19 (BOE de 12 de mayo); Orden INT/409/2020, de 14 de mayo, por la que se prorrogan los criterios para la aplicación de una restricción temporal de viajes no imprescindibles desde terceros países a la Unión Europea y países asociados Schengen por razones de orden público y salud pública con motivo de la crisis sanitaria ocasionada por el COVID-19 (BOE de 15 de mayo de 2020); Orden SND/439/2020, de 23 de mayo, por la que se prorrogan los controles en las fronteras interiores terrestres, aéreas y marítimas con motivo de la situación de crisis sanitaria ocasionada por el COVID-19 (BOE del mismo día); Orden SND/521/2020, de 13 de junio, por la que se prorrogan los criterios para la aplicación de una restricción temporal de viajes no imprescindibles desde terceros países a la Unión Europea y países asociados Schengen por razones de orden público y salud pública con motivo de la crisis sanitaria ocasionada por el COVID-19 (BOE de 15 de junio de 2020); Orden INT/551/2020, de 21 de junio, por la que se prorrogan los criterios para la aplicación de una restricción temporal de viajes no imprescindibles desde terceros países a la Unión Europea y países asociados Schengen por razones de orden público y salud pública con motivo de la crisis sanitaria ocasionada por el COVID-19 (BOE, de 22 de junio de 2020). Véase sectorialmente con Portugal: Orden INT/550/2020, de 21 de junio, por la que se prorrogan los controles en las fronteras interiores con Portugal temporalmente restablecidos con motivo de la situación de crisis sanitaria ocasionada por el COVID-19 (BOE de 22 de junio de 2020). 
ciudadanos españoles, residentes en España, trabajadores transfronterizos, personas con acreditación documental de "causas de fuerza mayor o situación de necesidad" y el personal diplomático acreditado (artículo único).

Asimismo, ha de traerse a colación la Orden INT/270/2020, de 21 de marzo, por la que se establecen criterios para la aplicación de una restricción temporal de viajes no imprescindibles desde terceros países a la Unión Europea y países asociados Schengen por razones de orden público y salud pública con motivo de la crisis sanitaria ocasionada por el COVID-1923. En este caso se establecen los supuestos de denegación de entrada "por motivos de orden público o salud pública, toda persona nacional de un tercer país" y la denegación de entrada "por motivos de orden público o salud pública a los ciudadanos de la Unión y sus familiares" (ambos supuestos con las correspondientes excepciones).

Mediante la Orden TMA/278/2020, de 24 de marzo ${ }^{24}$, por la que se establecen ciertas condiciones a los servicios de movilidad, en orden a la protección de personas, bienes y lugares, se prohíben expresamente los vuelos desde Italia (con algunas excepciones relativas a aeronaves de Estado, de carga, vuelos médicos, de emergencia, humanitarios o análogos ${ }^{25}$.

En esta primera fase debe señalarse la adopción de medidas restrictivas territorialmente restringidas. Así, anteriormente a la declaración del estado de alarma, el Ejecutivo catalán había dictado la Resolución INT/718/2020, de 12 de marzo de 2020, de la Generalitat de Cataluña, por la que se acuerda restringir la salida de las personas de los municipios de Igualada, Vilanova del Camí, Santa

\footnotetext{
${ }^{23}$ BOE de 22 de marzo de 2020.

${ }^{24}$ BOE de 25 de marzo de 2020 (la disposición ha sido derogada por la Orden TMA/419/2020, de 18 de mayo).

${ }^{25}$ Con carácter previo a la declaración del estado de alarma, el consejo de Ministros, mediante Acuerdos adoptados, el 10 de marzo de 2020 (BOE del mismo día) y el 12 de marzo de 2020 (BOE del mismo día; prorrogada por Orden TMA/330/2020, de 8 de abril, por la que se prorroga la prohibición de entrada de buques de pasaje procedentes de la República Italiana y de cruceros de cualquier origen con destino a puertos españoles para limitar la propagación y el contagio por el COVID-19, BOE de 9 de abril), dispuso, por un lado, la prohibición "de vuelos directos desde cualquier aeropuerto situado en la República de Italia a cualquier aeropuerto situado en el Reino de España" y, por otro lado, la prohibición de entrada en los puertos españoles de "buques de pasaje de transbordo rodado y buques de pasaje que presten servicio de línea regular entre puertos de la República de Italia y el Reino de España que hayan embarcado pasajeros en puerto italiano, con excepción de los conductores de las cabezas tractoras de la mercancía rodada", así como de "buques de pasaje tipo crucero procedentes de cualquier puerto", respectivamente. Las restricciones para este tipo de embarcaciones aún se mantenían con la Orden TMA/419/2020, de 18 de mayo, por la que se actualizan las medidas en materia de ordenación general de la navegación marítima adoptadas durante el estado de alarma para la gestión de la crisis sanitaria ocasionada por el COVID-19 al proceso de desescalada (BOE de 19 de mayo).
} 
Margarida de Montbui y Òdena, la cual establecía una serie de restricciones a la circulación de personas en los citados municipios durante un período de quince días naturales. Dada la subsistencia de las circunstancias que habían llevado a adoptar dichas restricciones, se dictó la Orden SND/290/2020, de 26 de marzo, por la que se prorroga la Resolución INT/718/2020, de 12 de marzo de 2020, de la Generalitat de Cataluña, por la que se acuerda restringir la salida de las personas de los municipios de Igualada, Vilanova del Camí, Santa Margarida de Montbui y Òdena ${ }^{26}$.

Primera prórroga del estado de alarma. Se produjo mediante Real Decreto $476 / 2020$, de 27 de marzo, por el que se prorroga el estado de alarma declarado por el Real Decreto 463/2020, de 14 de marzo, por el que se declara el estado de alarma para la gestión de la situación de crisis sanitaria ocasionada por el COVID19; prórroga previamente autorizada mediante Resolución de 25 de marzo de 2020, del Congreso de los Diputados, por la que se ordena la publicación del Acuerdo de autorización de la prórroga del estado de alarma declarado por el Real Decreto 463/2020, de 14 de marzo ${ }^{27}$.

En esta prórroga no se produce formalmente modificación de las medidas relativas a la libertad de circulación, pero sí se aprueba alguna norma "técnica" que afecta a la libertad de circulación, como la Orden SND/307/2020, 30 de marzo, por la que se establecen los criterios interpretativos para la aplicación del Real Decreto-ley 10/2020, de 29 de marzo, y el modelo de declaración responsable para facilitar los trayectos necesarios entre el lugar de residencia y de trabajo.

Segunda prórroga. Declarada por Real Decreto 487/2020, de 10 de abril, por el que se prorroga el estado de alarma declarado por el Real Decreto 463/2020, de 14 de marzo, por el que se declara el estado de alarma para la gestión de la situación de crisis sanitaria ocasionada por el COVID-19; prórroga previamente autorizada mediante Resolución de 9 de abril de 2020, del Congreso de los Diputados, por la que se ordena la publicación del Acuerdo de autorización de la prórroga del estado de alarma declarado por el Real Decreto 463/2020, de 14 de

${ }^{26}$ (BOE del mismo día), finalmente, las medidas se dejarían sin efecto mediante Orden SND/323/2020, de 5 de abril (BOE de 6 de abril de 2016).

${ }^{27}$ Ambos actos pueden consultarse en el BOE de 28 de marzo de 2020. 
marzo ${ }^{28}$. En ninguno de los actos se contiene previsión expresa sobre la libertad de circulación.

Nuevamente, con carácter territorialmente restringido, mediante Orden del Ministro de Sanidad, se pusieron fin a determinadas restricciones que afectaban al municipio de Arroyo de la Luz, en la Comunidad Autónoma de Extremadura, y que se había adoptado el 13 de marzo por parte del Vicepresidente Segundo y Consejero de Sanidad y Servicios Sociales de la Junta de Extremadura ${ }^{29}$.

Tercera prórroga. Se acuerda mediante Real Decreto 492/2020, de 24 de abril, por el que se prorroga el estado de alarma declarado por el Real Decreto 463/2020, de 14 de marzo, por el que se declara el estado de alarma para la gestión de la situación de crisis sanitaria ocasionada por el COVID-19, que fue autorizada por Resolución de 22 de abril de 2020, del Congreso de los Diputados, por la que se ordena la publicación del Acuerdo de autorización de la prórroga del estado de alarma declarado por el Real Decreto 463/2020, de 14 de marzo ${ }^{30}$.

La principal novedad se produce cuando puede observarse cómo en la autorización parlamentaria de la prórroga se contienen los términos de la modificación del artículo 7 del RD 463/2020, de 14 de marzo, si bien formalmente no se contienen modificaciones sustanciales en las excepciones a las restricciones de la movilidad, más allá de que "los menores de 14 años podrán acompañar a un adulto responsable de su cuidado cuando este realice alguna o algunas de las actividades previstas en el apartado anterior", en un avance de las atenuaciones de las restricciones a la libertad de circulación que estaban por venir y para las cuales cobró especial importancia la habilitación en favor del Ministro de Sanidad que se contenía en el apartado 6 을 dicho precepto, en cuya virtud: "El Ministro de Sanidad podrá, en atención a la evolución de la emergencia sanitaria, dictar órdenes e instrucciones en relación con las actividades y desplazamientos a que se refieren los apartados primero a cuarto de este artículo, con el alcance y ámbito territorial que en aquellas se determine".

Pues bien, durante esta fase se producen las primeras atenuaciones de las restricciones de circulación:

\footnotetext{
${ }^{28}$ Ambos actos pueden consultarse en el BOE de 11 de abril de 2020.

${ }^{29}$ Orden SND/339/2020, de 12 de abril, por la que se dejan sin efecto las restricciones previstas en la Resolución de 13 de marzo de 2020, del Vicepresidente Segundo y Consejero de Sanidad y Servicios Sociales de la Junta de Extremadura por la que se acuerdan medidas preventivas en materia de salud pública en relación con el municipio del Arroyo de la Luz (BOE del mismo día).

${ }^{30}$ Ambos actos se publicaron en el BOE de 25 de abril de 2020.
} 
La primera, que dio lugar a algunos episodios de descoordinación gubernativa pasmantes, por la que se permitían determinados desplazamientos de la población infantil ${ }^{31}$;

La segunda, que permitía la actividad física al aire libre bajo determinadas circunstancias $^{32}$, entre las que destacan, por su conexión con la libertad de circulación: la delimitación horaria para la práctica de la actividad deportiva y los límites espaciales en los que había de realizarse.

La tercera, en orden a permitir el desplazamiento a huertos y la realización de determinadas actividades agrícolas ${ }^{33}$.

La cuarta, flexibilizando determinadas restricciones sociales, pero con incidencia territorial limitada (islas de Formentera, la Gomera, el Hierro y la Graciosa) ${ }^{34}$.

Cuarta prórroga. Se acuerda mediante Real Decreto 514/2020, de 8 de mayo, por el que se prorroga el estado de alarma declarado por el Real Decreto 463/2020, de 14 de marzo, por el que se declara el estado de alarma para la gestión de la situación de crisis sanitaria ocasionada por el COVID-19, que fue autorizada por Resolución de 6 de mayo de 2020, del Congreso de los Diputados, por la que se ordena la publicación del Acuerdo de autorización de la prórroga del estado de alarma declarado por el Real Decreto 463/2020, de 14 de marzo.

La norma contiene alguna disposición relativa a la libertad de circulación: "En el marco de las decisiones que se adopten sobre la progresión de las medidas de desescalada, las personas podrán desplazarse por el territorio de la provincia, isla o unidad territorial de referencia que se determine a los efectos del proceso de desescalada, sin perjuicio de las excepciones que justifiquen el desplazamiento a otra parte del territorio nacional por motivos sanitarios, laborales, profesionales 0

\footnotetext{
${ }^{31}$ Orden SND/370/2020, de 25 de abril, sobre las condiciones en las que deben desarrollarse los desplazamientos por parte de la población infantil durante la situación de crisis sanitaria ocasionada por el COVID-19 (BOE del mismo día).

32 Orden SND/380/2020, de 30 de abril, sobre las condiciones en las que se puede realizar actividad física no profesional al aire libre durante la situación de crisis sanitaria ocasionada por el COVID-19 (BOE de 1 de mayo de 2020).

${ }^{33}$ Orden SND/381/2020, de 30 de abril, por la que se permite la realización de actividades no profesionales de cuidado y recolección de producciones agrícolas (BOE de 1 de mayo de 2020).

${ }^{34}$ Orden SND/386/2020, de 3 de mayo, por la que se flexibilizan determinadas restricciones sociales y se determinan las condiciones de desarrollo de la actividad de comercio minorista y de prestación de servicios, así como de las actividades de hostelería y restauración en los territorios menos afectados por la crisis sanitaria ocasionada por el COVID-19 (BOE del mismo día). En la norma se alude expresamente a que las nuevas medidas se adoptan en el marco del Plan para la transición hacia una nueva normalidad, aprobado por el Consejo de Ministros el 28 de abril de 2020.
} 
empresariales, de retorno al lugar de residencia familiar, asistencia y cuidado de mayores, dependientes o personas con discapacidad, causa de fuerza mayor o situación de necesidad o cualquier otra de análoga naturaleza"35.

Pues bien, sin perjuicio de normas muy sectorializadas (comercio minorista, práctica de deporte federado, transportes), la primer norma materialmente sustancial en la materia es la Orden SND/399/2020, de 9 de mayo, para la flexibilización de determinadas restricciones de ámbito nacional, establecidas tras la declaración del estado de alarma en aplicación de la fase 1 del Plan para la transición hacia una nueva normalidad (BOE del mismo día), que contiene prescripciones que atañen directamente a la libertad de circulación: la posibilidad de circulación por la provincia, isla o unidad territorial de referencia y que son concreción del real decreto de prórroga, como acaba de exponerse.

Por otro lado, en lo que respecta a la movilidad de las personas que, procedentes del extranjero, pretendieran ingresar en nuestro país, debían someterse a una cuarentena de 14 días (con vigencia durante todo el estado de alarma y sus prórrogas) ${ }^{36}$. No obstante la cuarentena dispuesta contiene excepciones por adquisición de alimentos, desplazamientos a centros sanitarios o causas de fuerza mayor.

La siguiente flexibilización sustancial se produjo a través de la Orden SND/414/2020, de 16 de mayo, para la flexibilización de determinadas restricciones de ámbito nacional establecidas tras la declaración del estado de alarma en aplicación de la fase 2 del Plan para la transición hacia una nueva normalidad (BOE del mismo día), en la que se incorporan disposiciones relativas a la actividad física no profesional de los mayores de 70 años; posteriormente, la Orden SND/458/2020, de 30 de mayo, para la flexibilización de determinadas restricciones de ámbito nacional establecidas tras la declaración del estado de alarma en aplicación de la fase 3 del Plan para la transición hacia una nueva normalidad (BOE del mismo día) suprimió las franjas horarias para todos los colectivos que estuvieran afectados por las mismas.

\footnotetext{
${ }^{35}$ Aunque la vertiente competencial no es materia del presente trabajo cumple destacar cómo, en relación con la libertad de circulación, "el Gobierno podrá acordar conjuntamente con cada Comunidad Autónoma la modificación, ampliación o restricción de las unidades de actuación y las limitaciones respecto a la libertad de circulación de las personas" (artículo 4).

${ }^{36}$ Orden SND/403/2020, de 11 mayo, sobre las condiciones de cuarentena a las que deben someterse las personas procedentes de otros países a su llegada a España, durante la situación de crisis sanitaria ocasionada por el COVID-19 (BOE de 12 de mayo).
} 
Quinta prórroga. Se acuerda mediante Real Decreto 537/2020, de 22 de mayo, por el que se prorroga el estado de alarma declarado por el Real Decreto 463/2020, de 14 de marzo, por el que se declara el estado de alarma para la gestión de la situación de crisis sanitaria ocasionada por el COVID-19, que fue autorizada por Resolución de 20 de mayo de 2020, del Congreso de los Diputados, por la que se ordena la publicación del Acuerdo de autorización de la prórroga del estado de alarma declarado por el Real Decreto 463/2020, de 14 de marzo ${ }^{37}$. El real decreto contenía dos normas relevantes en materia de libertad de circulación:

A) Mientras, por un lado, prevé que "la superación de todas las fases previstas en el Plan para la desescalada de las medidas extraordinarias adoptadas para hacer frente a la pandemia de COVID-19, aprobado por el Consejo de Ministros en su reunión de 28 de abril de 2020, determinará que queden sin efecto las medidas derivadas de la declaración del estado de alarma en las correspondientes provincias, islas o unidades territoriales".

B) Previamente se contiene la previsión de gobernanza en cuya virtud durante "el proceso de desescalada de las medidas adoptadas como consecuencia de la emergencia sanitaria causada por el COVID-19, el Gobierno podrá acordar conjuntamente con cada comunidad autónoma la modificación, ampliación o restricción de las unidades de actuación y las limitaciones respecto a la libertad de circulación de las personas"

Sexta prórroga. Acordada mediante Real Decreto 555/2020, de 5 de junio, por el que se prorroga el estado de alarma declarado por el Real Decreto 463/2020, de 14 de marzo, por el que se declara el estado de alarma para la gestión de la situación de crisis sanitaria ocasionada por el COVID-19, por la que se ordena la publicación del Acuerdo de autorización de la prórroga del estado de alarma declarado por el Real Decreto 463/2020, de 14 de marzo ${ }^{38}$. En las normas se reiteran las disposiciones expuestas en la anterior prórroga en materia de libertad de circulación.

3. La regresión: apuntes sobre la vuelta al estado de alarma y su incidencia sobre la libertad de circulación

\footnotetext{
${ }^{37}$ Publicación de ambos actos en el BOE de 23 de mayo de 2020.

${ }^{38}$ Ambos actos fueron publicados en el BOE de 6 de junio de 2020.
} 
A las cero horas del día veintiuno de junio concluía la sexta prórroga del estado de alarma y se iniciaba un periodo de fecundas y facundas innovaciones léxicas. Los ejes que delimitaban el rumbo eran una cuidadosa planificación gubernativa ${ }^{39}$ y una cogobernanza un tanto peculiar que, tras unos momentos iniciales de desentumecimiento, terminó a otras fórmulas medievales de organización política: ¿qué podía salir mal?

No corresponde analizar en un trabajo de esta naturaleza las vicisitudes sanitarias de la presente crisis, ni siquiera su gestión administrativa. Lo cierto es que la situación a la que ha llegado en octubre nos ha colocado de nuevo en el contexto de la emergencia constitucional, en el que en algunos territorios, la incidencia pandémica recordaba el desconcierto de los invitados de "La Máscara de la Muerte Roja".

- $\quad$ RD 900/2020, de 9 de octubre, por el que declara el estado de alarma para responder ante situaciones de especial riesgo por transmisión no controlada de infecciones causadas por el SARS-CoV-2.

La novedad más llamativa del decreto es su aplicación territorial limitada. Es cierto que, con ocasión del "primer estado de alarma pandémico" ya se pusieron de manifiesto algunas medidas con eficacia territorial limitada, con el objeto de prorrogar medidas limitativas de la libertad de circulación en determinados municipios de la comunidad autónoma catalana y que ya se habían adoptado con anterioridad a dictarse el RD 463/2020, pero la situación de emergencia constitucional declarada por este -y mantenida por sus subsiguientes prórrogasafectaban a todo el Estado (artículo 2 RD 463/2020). El RD 900/2020 no se aplica como errónea y simplificadamente se manifiesta en ocasiones a la Comunidad de Madrid, sino a los 9 municipios recogidos en el artículo 2.

Dadas las especiales características del supuesto de hecho que está en el origen de la emergencia, el derecho afectado (en realidad el único, a tenor de la norma) es la libertad de circulación. El contenido y alcance de la norma es simple, restringir la entrada y salida de los municipios contemplados con dos excepciones:

A) La realización de las actividades así conformadas por el decreto.

${ }^{39}$ El Plan para la transición hacia una nueva normalidad, aprobado por el Consejo de Ministros el 28 de abril de 2020, al que se ha aludido anteriormente. 
B) La circulación de personas en tránsito a través de los municipios concernidos por la norma.

- $\quad$ RD 926/2020, de 25 de octubre, por el que se declara el estado de alarma para contener la propagación de infecciones causadas por el SARS-CoV-2.

La parte dispositiva del decreto es antecedida por una exuberante prosa, estructurada en apartados, continuación de una práctica que inaugura el RD 492/2020, declaraba la tercera prórroga del estado de alarma, pero que concluye con la fórmula apodíctica y casi atrincherada entra los párrafos anteriores en orden a proclamar que las medidas adoptadas son imprescindibles, proporcionadas y no suspenden ningún derecho fundamental.

De nuevo estamos ante una norma cuya ámbito territorial es todo el territorio nacional (artículo 3) y que afecta a la libertad de circulación de la siguiente manera:

A) Introduce ex novo una medida limitativa de la libertad de circulación acotada en una determinada franja horaria marco (entre 23-6 h.; artículo 4), lo que viene siendo conocido como toque de queda, en la que se impide la circulación dejando a salvo excepciones relativas al cumplimientos de obligaciones laborales, razones sanitarias, de asistencia y otras análogas.

B) Restricción de la entrada y salida de las comunidades autónomas y ciudades con estatuto de autonomía, así mismo con previsión de un elenco de excepciones similar al anterior (artículo 6.1).

C) Habilitación a la autoridad competente delegada ${ }^{40}$ para restringir la entrada y salida en ámbitos territoriales inferiores al de la comunidad autónoma o ciudad con estatuto de autonomía (artículo 6.2) ${ }^{41}$.

El decreto contiene una serie de prescripciones sobre la eficacia de las limitaciones, en lo que aquí respecta: las limitaciones de entrada y salida deberán determinarse por la autoridad delegada según la evolución de los indicadores "epidemiológicos, sociales, económicos y de movilidad", sin que la medida pueda tener una eficacia temporal, en su caso, inferior a siete días (artículo 9.1). Por su parte, la medida de limitación de circulación durante una determinada franja

\footnotetext{
${ }^{40}$ El correspondiente Presidente de la comunidad autónoma o ciudad con estatuto de autonomía (artículo 2.2).

${ }^{41}$ Tanto en este caso como en el anterior queda exceptuada de la limitación la circulación en tránsito a través de los territorios sometidos a límites a la libertad de circulación (artículo 6.3).
} 
horaria se aplica en todo el territorio nacional, con previsión de un régimen específico para Canarias, en función de la inferior incidencia pandémica en el momento de dictar la norma (artículo 9.2).

La autoridad delegada podrá flexibilizar, modular o suspender la aplicación de las medidas limitativas de la libertad de circulación del artículo 6 (entrada y salida) de acuerdo con las condiciones señaladas en la norma, no así, sin embargo, la limitación de la circulación en la franja horaria.

\section{Reflexiones sobre las restricciones a la libertad de circulación}

Un supuesto de hecho como el que está en el origen de la presente situación de restricción de derechos y libertades justifica la afectación a la libertad de la circulación como instrumento para controlar la difusión de una enfermedad con algunas destacadas características como:

A) La elevada carga vírica que asegura una elevada transmisión por contagio.

B) La ausencia de vacuna que prevenga la infección.

C) La ausencia de tratamientos médicos definitivos.

Desde estos presupuestos, genéricas apelaciones al respeto de los derechos y libertades de las personas no pueden erigirse en un óbice para la intervención de los poderes públicos obligadas a salvaguardar, a su vez, otros derechos, bienes e intereses públicos.

Pero ello, en modo alguno nos releva del necesario y severo escrutinio al que ha de someterse cualquier medida limitativa de un derecho fundamental o una libertad pública. La necesidad de interpretar las restricciones a los derechos a la luz de los tratados internacionales que obligan a nuestro país desvela alguna clave interesante en este particular, cuando de la lectura de artículo 2 del Protocolo 4 al Convenio Europeo de derechos Humanos puede advertirse que el ejercicio de la libertad de circulación "no puede ser objeto de más restricciones que las que, previstas por la ley, constituyen medidas necesarias, en una sociedad democrática, para la seguridad nacional, la seguridad pública, el mantenimiento del orden público, la prevención del delito, la protección de la salud o de la moral, o la protección de los derechos y libertades de terceros" ${ }^{42}$. Sin

\footnotetext{
${ }^{42}$ Sin cursivas en el original.
} 
embargo, la sola invocación de la salud (incluso en conexión con la protección de los derechos de terceros) no justifica cualquier inmisión en la libertad de la circulación, que requiere previsión legal ${ }^{43}$, necesidad y proporcionalidad ${ }^{44}$.

Nuestro Tribunal se ha autoacantonado en la supervisión de que el recurso a los estados excepcionales del artículo 116 CE no vulnera los derechos fundamentales comprometidos en cada caso, "desterrando" al recurso de amparo de la fiscalización de los actos de declaración y prórroga de los mismos en este cometido, en un proceso que arranca con el ATC 7/2012, de 13 de enero, y que, por el momento, culmina en la STC 83/2016, de 31 de mayo. En este contexto, el recurso de amparo queda confinado al contraste de los actos que los poderes públicos dicten en ejecución de este tipo de actos, reservando la declaración y prórroga de los estados excepcionales para el control de constitucionalidad ${ }^{45}$.

Con todo, posiblemente una de las cuestiones "litigiosas" que más vienen ocupando a quienes examinan esta cuestión es la idoneidad del estado de alarma como instrumento para acometer la restricción de los derechos fundamentales si el resultado de las limitaciones impuestas es el de su suspensión, habida cuenta que el artículo 55.1 CE restringe esta posibilidad a los estados de excepción y de sitio, no así al de alarma. La cuestión vendría dada porque un examen de la intensidad de la restricción que han padecido los derechos y libertades afectados por el "primer estado de alarma pandémico", al que en realidad se ciñen estas líneas, desvelaría un resultado más suspensivo que meramente restrictivo ${ }^{46}$.

La cuestión radica en el supuesto bajo cuyo amparo puede acudirse al estado de excepción, que parece reservado a graves crisis de orden público con una alteración del orden público de tal intensidad "que el ejercicio de las potestades

\footnotetext{
${ }^{43}$ Como también exige nuestro propio Tribunal Constitucional: STC 85/1989, de 10 de mayo, FJ 3.

${ }^{44}$ En el ámbito del Convenio, véase sobre este particular el amplio trabajo de Arenas Hidalgo, $\mathrm{N}$. (2014): en especial 762-768.

${ }^{45}$ Véase, en consecuencia, la inadmisión por parte del Tribunal Supremo, por falta de jurisdicción, de un recurso contencioso-administrativo planteado contra el decreto de declaración del estado de alarma y sus ulteriores prórrogas, en el que se alegaba infracción de derechos fundamentales (entre otros libertad circulación); la referencia se ha obtenido del portal poder Judicial, en noticia fechada el 4 de mayo de 2020 y que puede consultarse en $<$ http://www.poderjudicial.es/cgpj/es/Poder-Judicial/Sala-de-Prensa/Archivo-de-notas-deprensa/El-Tribunal-Supremo-inadmite-el-recurso-presentado-por-un-particular-por-posiblevulneracion-de-derechos-fundamentales-por-el-Estado-de-alarma>

${ }^{46}$ Puede encontrarse una síntesis de las posiciones doctrinales en este sentido en Nogueira López, Alba (2020): 26. La propia autora parece decantarse que, a la vista de las restricciones acordadas, el supuesto más respetuoso con el tenor del artículo 55.1 CE hubiera sido el recurso al estado de excepción (27).
} 
ordinarias fuera insuficiente para restablecerlo y mantenerlo" (artículo 13.1 LO 4/1981). Es verdad que no faltan opiniones, al examinar los supuestos que, según el Convenio de Roma, habilitan para adoptar restricciones a la libertad de circulación en sentido de considerar que todas "pudieran encuadrarse en una noción amplia de «orden público»" 47 , pero creo que ello supone una flagrante desviación del sentido de la norma española, tal y como está redactada. Y, en la redacción actual, el supuesto de hecho que ha llevado al estado de emergencia constitucional concuerda con los reservados al estado de alarma en el artículo 4, letra b) y c) LO 4/1981.

Opciones de futuro para adecuar el marco normativo no faltan, toda vez que la Constitución no precisa el ámbito material de cada uno de los estados excepcionales. Así, nada obstaría para, dejando el estado de alarma como está, modificar el estado de excepción e introducir, junto con los supuestos actualmente contemplados, aquellos del estado de alarma cuando, por así decirlo, un uso ordinario del mismo no fuera suficiente para solventar la crisis y se requirieran restricciones que supusieran la suspensión de los derechos fundamentales.

Ahora bien, volviendo al estado de alarma objeto de estas consideraciones, ¿realmente las restricciones impuestas a la libertad de circulación han supuesto una suspensión del derecho con contravención del artículo 55.1 CE? A falta aún de que el Tribunal Constitucional se pronuncie, pueden hacerse algunas reflexiones sustentadas en determinar el enfoque correcto para aproximarse a esta cuestión. La "sensación" de que hemos tenido suspendida la libertad de circulación es consecuencia, creo, de una perspectiva que se ubica en la intensidad, en el alcance de la restricción. Ayunos -afortunadamente- de praxis sobre el estado de excepción es inevitable, hasta cierto punto, que surja la pregunta: ¿qué mayor restricción que la padecida hasta el momento, en relación con la libertad de circulación, serían posibles para referirse en rigor a un supuesto de suspensión?

No considero que la respuesta arroje resultados satisfactorios, mover la aguja, si se me permite la expresión, hacia la suspensión o hacia la restricción se antoja una operación poco objetiva y localizada en un terreno donde los matices correrían el riesgo de deslucir la necesaria certeza en la materia.

\footnotetext{
${ }^{47}$ Así, Arenas Hidalgo, N. recogiendo las tesis de F. Sudre (2014: 763).
} 
fundación

Manuel Giménez Abad

deEstudios Parlamentariosydel Estado Autonómico

Como la propia práctica está desvelando -parcialmente al menos- la cuestión se antoja más cercana a la conexión entre invocación-tutela de los derechos concernidos. La suspensión de los derechos contrae la tutela al examen material del supuesto concreto por parte del Tribunal Constitucional, pudiendo estimarse la inconstitucionalidad de la declaración -o de la prórroga- por inexistencia contrastada de supuesto de hecho que la sustente. La restricción hace posible invocar el derecho ante el juez impetrando su tutela (así ha sucedido con el derecho de reunión y manifestación e, incluso, ante la libertad de circulación frente a sanciones de actuaciones de los particulares que el juez ha encontrado perfectamente justificadas), no así en la suspensión que, mientras dure la vigencia del estado excepcional, hace imposible alegaciones de esta naturaleza.

No son ni mucho menos reflexiones concluyentes, reservar al dominio del juez el ejercicio de los derechos en este contexto conduce, como poco, a eventuales soluciones dispares (como también ha podido verse).

\section{BIBLIOGRAFÍA}

- ÁlVAREZ GARCÍA, V. (2020). "El Coronavirus (Covid-19): respuestas jurídicas frente a una situación de emergencia sanitaria", El Cronista del Estado Social y Democrático de Derecho, núm. 86-87, marzo-abril 2019, pp. 5-19.

- Álvarez garcía, V., ARUAS APARICIO, F. y heRnÁNDEZ díEZ, E. (2020). "Una cronología jurídica comentada del estado de alarma declarado para la lucha contra la pandemia de coronavirus (Covid-19)", El Cronista del Estado Social y Democrático de Derecho, núm. 86-87, marzo-abril 2019, pp. 112-127.

- ARENAS HIDALGO, N. (2014): "XXXII: La libertad de circulación en el territorio de los Estados. (La libertad deambulatoria definida en el artículo 2 del Protocolo Adicional 4. ${ }^{\circ}$ al CEDH", La Europa de los derechos. El Convenio Europeo de Derechos Humanos (Dir. J. García Roca y P. Santolaya), Centro de Estudios Políticos y Constitucionales, Madrid, 2014 (3.a ed.), pp. 743-772.

- BASTIDA FREIJEDO, F. "Libertad de circulación”, en: Temas básicos de Derecho Constitucional (Coord. M. Aragón Reyes), T. III, Civitas, Madrid, 2001, pp. 153-155. 
— DELGADO RAMOS, D. (2018). "Artículo 19", en: Comentarios a la Constitución española de 1978 (Dir. L. M. a Cazorla Prieto, Coord. A. Palomar Olmeda), T. I, Thomson Aranzadi, Cizu Menor, 2018, pp. 476-490.

- DÍEZ-PICAZO, L. Mํ․ (2005). Sistema de Derechos fundamentales, Thomson Civitas, Madrid, 2005 (2..$^{\mathrm{a}}$ ed.).

- GoIZUETA VÉRTIZ, J. (2018). "Artículo 19", Comentario a la Constitución española 40 Aniversario 1978-2018. Libro-homenaje a Luis López Guerra (Dir. P. Pérez Tremps y A. Saiz Arnaiz), T. I, Valencia, 2018, Tirant lo Blanch, pp. 455563.

- LOSADA GONZÁLEZ, H. (2018). "Artículo 19", Comentarios a la Constitución española (Dir. M. Rodríguez-Piñero y M. ${ }^{a}$ E. Casas), T. I, Wolters Kuwer-BOE y otros, Madrid, 2018, pp. 567-579.

- NOGUEIRA LÓPEZ, A. (2020). "Confinar el coronavirus. Entre el viejo Derecho sectorial y el Derecho de Excepción”, El Cronista del Estado Social y Democrático de Derecho, núm. 86-87, marzo-abril 2019, pp. 20-29.

- PRESNO LINERA, M. (2020). "Estado de alarma por coronavirus y protección jurídica de los grupos vulnerables", El Cronista del Estado Social y Democrático de Derecho, núm. 86-87, marzo-abril 2019, pp. 52-63. 